\title{
Letramento em tempos de novas tecnologias de informação, comunicação e expressão
}

\author{
Lucy Mirian Campos Tavares Nascimento
}

Lenise Aparecida Martins Garcia

\begin{abstract}
Resumo
A comunicação é um processo inerente ao ser humano, que, ao longo da sua história, vem desenvolvendo tecnologias para promovê-la. Desde a invenção da grafia até os mais complexos sistemas computacionais, as competências sociais têm se modificado e exigido novos mecanismos de apropriação da escrita e da leitura. Nesta década, uma das marcantes necessidades está relacionada ao domínio contextualizado e consciente das competências de escrita e leitura, que também preparam para atuar de forma presente na sociedade digital. Tais competências têm se apresentado um desafio ao sistema educacional, que não está preparado para lidar com a geração de nativos digitais, os quais nasceram em um mundo tecnológico e, portanto, são usuários natos dessas ferramentas. Nesse arcabouço, as novas tecnologias de informação, comunicação e expressão (NTICE) se apresentam como ferramentas promissoras para aproximar o fazer pedagógico dos professores às necessidades letradas da sociedade telemática.
\end{abstract}

Palavras-chave: letramento, novas tecnologias, alfabetização científica, nativo digital, imigrante digital.

\section{Abstract \\ Literacy at times of new information technologies, communication and expression}

Communication is a process inherent to human beings, for throughout their evolution, they have developed their own technologies to promote it. Since the invention of writing to the most complex computer systems, social skills have changed and required new mechanisms for appropriation of writing and reading. In this decade one of the striking collections is related to the contextual conscious domain of the writing and reading competences, that also prepar to act accordingly in the digital society. Such skills have presented a challenge to the educational system, which is not prepared to deal with the generation of digital natives, who were born in a technological world and therefore are native users of these tools. In this framework, the new information technologies, communication and expression (ICETs) are presented as promising tools to approach teacher's pedagogical practice to the literate needs of telematics society.

Keywords: literacy, new technologies, scientific literacy, digital native, digital immigrant. 


\section{Introdução}

A necessidade de se comunicar é inerente aos seres vivos, principalmente os que vivem em sociedade. Mas somente o homem é capaz de manipular a informação e registrá-la de forma consciente e intencional. Fazer-se entender, transmitir e receber uma informação são ações que podem ser constatadas desde os períodos pré-históricos por meio das pinturas rupestres (PEREIRA, MARQUES e TORRES, 1998). Desde então, a comunicação escrita ganhou condição de simbologia social.

A grafia é uma tecnologia criada e desenvolvida pelo homem. Os seus símbolos e signos linguísticos possibilitaram-nos perpetuar uma ideia, transmitir informações de uma cultura para outra, independente do tempo e do espaço. A grafia é, portanto, o meio; sendo a leitura, uma forma de apropriação desse mecanismo.

Ao longo do desenvolvimento humano, outras tecnologias relacionadas à comunicação foram sendo desenvolvidas e incorporadas a nossa cultura. Podemos citar o caso da prensa com tipos móveis, criada por Gutenberg em 1450, invenção que possibilitou a milhares de pessoas o acesso a inúmeras informações. Depois vieram as máquinas fotográficas, o cinema, a televisão, os computadores, a internet e as redes sociais virtuais.

Todo esse aparato tecnológico desenvolvido pelo homem foi interferindo na própria dinâmica da comunicação e, consequentemente, no uso e domínio das competências de escrita e leitura. A forma como as pessoas leem e escrevem sofreu modificações em virtude desse processo de interação. O homem modifica a tecnologia e também se transforma ao incorporá-la às suas práticas; afetando, inclusive, a forma como processa a informação.

A introdução de uma nova tecnologia nem sempre está atrelada à substituição das tecnologias que a antecederam. No caso da prensa, por exemplo, os tipos não substituíram os manuscritos. A invenção da televisão não substituiu o cinema. Na maioria das vezes, as tecnologias mais avançadas incorporam aquelas que as precederam ou mesmo caminham lado a lado influenciando-se.

Contudo, as maiores mudanças provocadas pelas tecnologias não se centram na materialidade ou virtualidade do mecanismo de transmissão e obtenção da informação, mas, sim, na forma com a qual o homem se apropria e usufrui da comunicação da informação.

Será que podemos considerar que a comunicação evoluiu? Dos grunhidos do homem primitivo aos grunhidos do homem moderno nas redes sociais (exemplificável por meio de construções como rsrsrs, kkkkk, hehehe), o que mudou no processo comunicativo? A complexidade comunicativa se ampliou ou temo-nos perdido em inúmeros posts e hiperlinks?

Bechelloni (2012) chama-nos a atenção sobre a má e a boa comunicação, destacando que o conhecimento expressa as "coisas do mundo", sendo os mecanismos de alfabetização 
aprendidos na experiência cotidiana e atualmente marcados pelos meios de comunicação e pela sociedade de consumo. Segundo ele, ao não serem mediatizados pelas instituições de ensino e pelo ser humano, se banalizam e ganham corpus de verdades nem sempre fidedignas.

Tais apontamentos nos levam a indagar sobre a necessidade do ser humano de se manifestar nas redes sociais. Os crescentes manifestos nas mídias sociais demonstram o poder desses ambientes em mobilizar presencialmente milhares de pessoas, com diferentes propósitos. Nas diversas manifestações que ganharam o cenário nacional e internacional, inicialmente desencadeadas pelo protesto 'tarifa zero', vimos isso, mas percebemos também a completa falta de articulação política entre os manifestantes.

Segundo Castells (2013), as redes sociais possibilitaram ao usuário articular, no mundo virtual, manifestações sociais no espaço público. Antes isso só acontecia mediante a organização de grupos políticos, ou seja, as manifestações eram organizadas com finalidades pré-definidas e tinha-se certa centralidade nos grupos de poder. Agora não, todos têm voz e querem ser ouvidos. Comunicar é preciso, mas comunicar o que, para quem, e com qual objetivo?

\section{Alfabetização científica e letramento científico, competências necessárias à formação cidadã}

A prática social da leitura e da escrita, no contexto da sociedade globalizada e digital, envolve o emprego do conhecimento de forma a dar respostas às necessidades do cidadão. Frente a diversas concepções sobre alfabetização e letramento, alfabetização científica e letramento científico, cabe evidenciarmos o sentido desses termos aqui empregado.

Ao se tratar a alfabetização como a ação de alfabetizar, limita-se essa atividade ao ensinamento do alfabeto, ou seja, ao ensinar a ler e a escrever contemplamos o "domínio da tecnologia - do conjunto de técnicas - para exercer a arte e a ciência escrita" (SOARES, 2003, p.80).

Já a palavra letramento vem do latim littera, que significa letra. Já o sufixo - cy denota qualidade, condição, ou seja, literacy é o "estado ou condição que assume aquele que aprende a ler e escrever" (SOARES, 1998, p.17).

Mamede e Zimmermann (2005) descrevem a alfabetização como domínio do conhecimento e das habilidades de leitura e escrita num âmbito pessoal, enquanto o letramento seria o uso efetivo dessas práticas num âmbito social. Essa concepção de letramento encontra consonância nas ideias de Freire ao afirmar que: "o domínio sobre os signos linguísticos escritos, mesmo pela criança que se alfabetiza, pressupõe uma experiência social que o precede - a da 'leitura' do mundo" (FREIRE, 1978, p.60). Para ele a "alfabetização passa por questões de ordem lógico-intelectual, afetiva, sociocultural, política e técnica” (FREIRE,1996, p.60). 
Com enfoques diferentes, porém correlacionados, a alfabetização e o letramento podem ser considerados duas faces de uma mesma moeda, sendo este último o uso social consciente das ações de ler e escrever. Consideramos, portanto, o letramento no sentido de alfabetização empregado por Paulo Freire (1967, p.117):

"[...] é mais do que o simples domínio psicológico e mecânico de técnicas de escrever e de ler. É o domínio dessas técnicas, em termos conscientes. É entender o que se lê e escrever o que se entende. É comunicar-se graficamente. É uma incorporação. Implica não uma memorização visual e mecânica de sentenças, de palavras, de sílabas, desgarradas de um universo existencial coisas mortas ou semimortas - mas uma atitude de criação e recriação. Implica uma autoformação de que possa resultar uma postura interferente do homem sobre seu contexto".

Percebe-se que o sentido de alfabetização apresentado por Freire (1967) defende a plena formação do sujeito. Ser alfabetizado é aqui entendido como ser letrado e capaz de compreender e inferir em diversos gêneros linguísticos, ou seja, esse sujeito se apropria efetivamente do saber. Letramento, visto que, segundo Soares (2003, p.92), trata-se do:

"[...] exercício efetivo da tecnologia da escrita, [...] que implica habilidades várias, tais como: capacidade de ler ou escrever para atingir diferentes objetivos - para informar ou formar-se, para interagir com outros, para imergir no imaginário, no estético, para ampliar conhecimentos, para seduzir ou induzir, para divertir-se, para orientar-se, para apoio à memória, para catarse ...; habilidades de interpretar e produzir diferentes tipos e gêneros de textos; habilidades de orientar-se pelos protocolos de leitura que marcam o texto ou de lançar mão desses protocolos ao escrever [...]".

Os termos alfabetização científica e letramento científico também apresentam na literatura diversas concepções, muitas vezes sobrepondo-se. Porém, para nós e para Mamede e Zimmermann (2005), a alfabetização científica e o letramento científico apresentam significados próprios. Elas entendem a "alfabetização científica, como sendo referente à aprendizagem dos conteúdos e da linguagem científica. Por outro lado, o letramento científico se refere ao uso do conhecimento científico e tecnológico no cotidiano, no interior de um contexto sócio-histórico específico" (MAMEDE E ZIMMERMANN, 2005, p.2).

Santos (2007, p. 479) é outro autor que opta em diferenciar a alfabetização científica do letramento científico, apoiado no entendimento de que "na tradição escolar a alfabetização científica tem sido considerada na acepção do domínio da linguagem científica, enquanto o letramento científico, no sentido do uso da prática social, parece ser um mito distante da prática de sala de aula". 
Diante do exposto, percebe-se a necessidade de romper com o desafio de letrar cientificamente os educandos, a fim de Ihes proporcionar um conhecimento científico que seja um instrumento de empoderamento, na perspectiva de lhes proporcionar condições de compreender o contexto social e atuar de forma proativa na sociedade.

Tal sentido é apresentado por Hazel; Trefil (1995, p.12), mas com a rotulagem de alfabetização. Segundo eles, alfabetizar "ter o conhecimento necessário para entender os debates públicos sobre as questões de ciência e tecnologia". Há uma distinção entre ser capaz de fazer ciência e ser capaz de usar a ciência, pois a literacia científica, pura e simples, é uma mistura de conceitos, história e filosofia que ajuda a compreender as questões científicas do nosso dia a dia (HAZEL, 2002).

Esclarecidas as concepções de alfabetização científica e letramento científico, convém apontar as competências e habilidades necessárias ao pleno letramento científico do sujeito, que, de acordo com Mamede e Zimmermann (2005), envolve três dimensões que se complementam: a prática, a cívica e a cultural. A primeira capacita o homem a utilizar os conhecimentos científicos para resolver problemas cotidianos. A segunda permite que ele compreenda os problemas que envolvem as ciências e as tecnologias. E a última leva os indivíduos a se capacitarem acerca das ciências e da tecnologia, aprofundando seus conhecimentos.

Considerando que a formação cidadã envolve as práticas sociais de leitura e escrita e estas envolvem a alfabetização científica e o letramento científico, a escola e os professores devem promover situações de ensino-aprendizagem que colaborem para o domínio dessas competências. Conforme destacado nos Parâmetros Curriculares Nacionais do Ensino Médio (PCNEM), a formação básica do aluno deve-se pautar na "preparação científica e a capacidade de utilizar as diferentes tecnologias relativas às áreas de atuação" (BRASIL, 2000, p.5) ainda que a educação deva centrar-se na preparação do aluno quanto a dar significação ao conhecimento escolar, contextualizando-o, mediante a interdisciplinaridade.

Nessa perspectiva cabe à escola e aos educadores apropriarem-se de tecnologias pedagógicas que colaborem para que o educando possa atuar na sociedade de forma ativa, posicionando-se frente a situações cotidianas que exijam dele a leitura e a discussão crítica dos fatos, calcadas no conhecimento científico e tecnológico.

Para atingir tais objetivos, é necessário estimular os estudantes a desbravarem o universo textual existente, o que inclui experimentar a sua inserção em diversos gêneros linguísticos, como a leitura de livros, jornais, artigos, receituários, blogs, e-mails, hipertextos entre tantos outros. Além disso, a percepção de letramento científico colabora com a prática pedagógica do educador de forma que ele possa ter como foco a aprendizagem dos alunos num sentido interdisciplinar das ciências. Nesse sentido "a participação do cidadão na vida social de uma maneira ampla depende de sua possibilidade de interlocução com questões complexas baseadas em conhecimentos 
científicos e tecnológicos" e não na memorização descontextualizada de conceitos e fórmulas que não se aproximam da realidade (MAMEDE; ZIMMERMAN, 2005, p. 2).

\section{A escola e suas atribuições no letramento}

A ação de comunicar vai além do mero repasse de informação. Pressupõe que a mensagem produzida por um emissor seja não somente recebida, mas compreendida pelo receptor.

A comunicação pode, portanto, ser entendida como uma arte, que dá àquele que sabe bem empregá-la o domínio da razão, a verdade pronunciada. Ter o domínio dessa arte é um bem tão precioso que, durante muitos séculos, foi cultuada somente por uma minoria privilegiada. As escolas, no princípio, surgiram com os filósofos, os quais possuíam poder aquisitivo suficiente para se manterem, dedicarem-se a seus estudos e compartilharem seus conhecimentos com outros do mesmo grupo social. Depois vieram a burguesia, os religiosos e alguns poucos contemplados que podiam contar com o aprendizado formal ${ }^{1}$.

Com o desenvolvimento acelerado pela Revolução Industrial, surgiu a necessidade de qualificar mão de obra para trabalhar nas mais diversas áreas, não somente nas indústrias, mas em todos os segmentos que davam suporte à manutenção desse gigantesco mecanismo. A sociedade então delegou essa formação às escolas, surgindo os cursos técnicos e ampliando-se o processo de alfabetização da população.

Percebemos que a sociedade incumbiu à escola o papel institucional de formadora de cidadãos, de acordo com suas necessidades. Nesse sentido esta tem buscado, ao longo de sua história, se adequar a esses propósitos. Contudo a dinamicidade desencadeada pelas tecnologias de comunicação que influenciaram todos os setores da sociedade ainda não se faz plenamente contemplada nas escolas, especialmente nas escolas públicas.

Atualmente, no Brasil, a educação básica é regulamentada pela Constituição Nacional e tem como diretrizes norteadoras a Lei de Diretrizes e Bases (LDB) e o Plano Nacional de Educação (PNE). Tais instrumentos legais foram criados para melhor estruturar a educação no país.

Nesses documentos destaca-se a preocupação com o domínio da escrita e da leitura para a aquisição de habilidades que colaborem para a formação do cidadão. $O$ art. 32 da LDB declara que o objetivo do Ensino Fundamental é "o desenvolvimento da capacidade de aprender,

1 De acordo com Bianconi e Caruso (2005), "a educação formal pode ser resumida como aquela que está presente no ensino escolar institucionalizado, cronologicamente gradual e hierarquicamente estruturado, e a informal como aquela na qual qualquer pessoa adquire e acumula conhecimentos, mediante experiência diária em casa, no trabalho e no lazer".

R. B. E. C. T., vol 8, núm. 3, mai-ago.2015 ISSN - 1982-873X

DOI: Em andamento. 
tendo como meios básicos o pleno domínio da leitura, da escrita e do cálculo." (BRASIL, 2004, p.14).

Já no PNE há uma referência específica quanto à Educação de Jovens e Adultos (EJA) (BRASIL, 2001, p. 50), destacando que:

“[...] para inserir a população no exercício pleno da cidadania, melhorar sua qualidade de vida e de fruição do tempo livre e ampliar suas oportunidades no mercado de trabalho, a educação de jovens e adultos deve compreender, no mínimo, a oferta de uma formação equivalente às oito séries iniciais do ensino fundamental".

Buscando essa compreensão, o domínio da escrita e da leitura se manifesta como essencial à prática cidadã que a sociedade almeja. Não basta que as pessoas saibam decifrar os códigos, mas compreender, dentro de um contexto, o que eles significam e conseguir utilizar esses saberes na resolução de problemas cotidianos. Isto é muito mais que ser alfabetizado, é ser letrado.

Segundo os Parâmetros Curriculares Nacionais (PCN) de Português (BRASIL, 1997), um dos motivos do fracasso escolar no ensino fundamental está relacionado à falta de domínio da leitura e da escrita. Essa dificuldade é também encontrada no ensino superior, no qual, segundo esses documentos, os alunos não conseguem entender os textos propostos, nem transcrever o que entenderam de forma legível, levando as universidades a modificarem os processos de avaliação para os ingressos, inserindo questões dissertativas e valorizando a redação.

Centrados na proposição de colaborar na resolução de tais problemáticas, os PCN de Português ressaltam como objetivo do Ensino Fundamental a importância de desenvolver nos alunos competências quanto ao uso da língua, para que possam empregá-la na resolução de problemas cotidianos, ter acesso aos bens culturais e poder participar plenamente do mundo letrado. Para isso, cabe à escola, ao ensinar, "a responsabilidade de garantir a todos os seus alunos o acesso aos saberes linguísticos, necessários para o exercício da cidadania, direito inalienável de todos" (BRASIL, 1997, p.15).

O domínio da linguagem permite ao educando efetiva participação social, uma vez que essas competências podem ser compreendidas como libertadoras, pois capacitam o homem a ler com seus próprios olhos (MARTINS, 1994). Nesse entendimento, Paulo Freire foi um dos grandes defensores da educação como processo fundamental à prática democrática consciente, libertadora. Para ele o real sentido da alfabetização "é a consequência de uma reflexão que o homem começa a fazer sobre sua própria capacidade de refletir" (FREIRE, 1967, p. 149).

Há de se ressaltar que a responsabilidade de desenvolver as competências de leitura e escrita não se restringe apenas ao professor de português; trata-se de um compromisso que deve 
ser assumido pelos professores de todas as áreas, uma vez que cada disciplina tem seus códigos próprios e os alunos necessitam ser inseridos nessa cultura comunicativa.

É necessário que os professores das diversas áreas, desde a sua formação inicial, sejam preparados a incentivar os alunos na prática da leitura e da escrita de forma contextualizada. Talvez isso não ocorra efetivamente por falta de compreensão quanto ao seu papel como educador, restringindo-se apenas à transmissão de informação da sua disciplina. Mas cada disciplina pode colaborar nessa formação usufruindo dos diversos gêneros linguísticos, como leitura de revistas e textos jornalísticos, leitura e interpretação de gráficos e tabelas, relatos de experiências, portfólios, produção de documentários, imagens, charges etc.

A leitura e a escrita devem ser vistas na escola como prática social capaz de levar o aluno não somente a decifrar os códigos, mas ser capaz de fazer conexões do que leu ou ouviu com a realidade política, econômica, social e cultural na qual esta informação está inserida. De acordo com Freire (1967, p.12), "todo aprendizado deve encontrar-se intimamente associado à tomada de consciência da situação real vivida pelo educando". Por isso, à educação cabe uma formação integral do aluno com fins de informar e intervir no mundo e estar-no-mundo, sermundo. Como destacado por Freire $(1967$, p.39):

“É fundamental, contudo, partirmos de que o homem, ser de relações e não só de contatos, não apenas está no mundo, mas com o mundo. Estar com o mundo resulta de sua abertura à realidade, que o faz ser o ente de relações que é".

\section{Letramento e novas tecnologias de informação, comunicação e expressão (NTICE)}

O mundo contemporâneo tem como um dos marcos as rápidas e profundas transformações proporcionadas pela internet e suas ferramentas. Elas têm interferido e modificado a visão de mundo que o homem possuía, promovendo uma global revolução cultural. Segundo Lévy (1999), isso acontece porque as ferramentas digitais mudaram os hábitos das pessoas e com isso alterou-se a forma como processam a informação, como pensam, se relacionam e aprendem. Isso é produto do grande volume de interações envolvidas e das múltiplas possibilidades existentes no espaço virtual, promovidas pelos hiperlinks, que possibilitam ao usuário migrar a qualquer instante para outra página que lhe seja mais agradável. 
Pesquisas realizadas pelo Programa Internacional de Avaliação de Estudantes (PISA) ${ }^{2}$ (BRASIL, 2010) procuram avaliar, em vários países, as competências de jovens no que se refere ao letramento. Como competências, esses exames destacam a capacidade do estudante de ir além dos conhecimentos aprendidos na escola, sabendo analisar, refletir, interpretar, colocar e solucionar problemas em uma infinidade de situações. Segundo dados do PISA de 2009, os estudantes brasileiros não apresentam competência suficiente para resolver situações cotidianas, mesmo as mais simples. Nessa pesquisa o Brasil ocupou o 54일 lugar de um total de 65 países participantes, o que ilustra a gravidade da situação (BRASIL, 2010).

Além desses, outros problemas são apontados por pesquisadores como colaborando para o baixo rendimento dos alunos: desmotivação profissional, falta de competência na escrita e na leitura, evasão escolar, repetência etc. (MAMEDE e ZIMMERMANN, 2005; PINHO, 2012). O motivo disso, segundo Prensky (2001), está no fato dos avanços tecnológicos dos últimos 20 anos do século XX terem promovido o surgimento da geração digital, com a qual o sistema educacional não está preparado para lidar.

Esse autor destaca o distanciamento existente entre os nativos digitais e os imigrantes digitais. O termo "nativo digital", cunhado por Prensky (2001), designa os jovens que nasceram em um mundo cercado pela tecnologia e dela usufruem naturalmente. Basta verificarmos como as crianças lidam naturalmente com celulares, controles remotos, computadores, jogos eletrônicos etc. Eles aprendem a lidar com tais instrumentos de forma interativa, na tentativa de erro e acerto. São multimidiáticos, ou seja, interagem com várias informações ao mesmo tempo.

Já aqueles que não nasceram nesse mundo digital, ou a ele só tiveram acesso mais tardiamente, são considerados "imigrantes digitais" (Ibidem, 2001) e, como todo imigrante, trazem consigo resquícios de sua cultura, apresentando estrutura mais linear de aprendizagem. Ainda procuram aprender o uso das tecnologias em manuais, costumam ligar para uma pessoa para verificar se ela recebeu um e-mail, por exemplo. Escrevem textos longos a mão para então digitá-los ou ainda imprimem textos para lê-los.

Certamente não há como negar que as novas gerações lidam com as NTICE de forma diferente. Isso não significa que devamos imputar às ferramentas tecnológicas todas as culpas e redenções, mas implica estarmos atentos ao nosso foco, o aluno, e perceber aquilo que o atrai, que prende sua atenção, compreender como processa a informação, como a obtém e o uso que faz dela. É necessário nos aproximarmos do nosso objetivo, que é fazer com que o educando

2 Exame realizado trienalmente nos países pela OCDE (Organização para Cooperação e Desenvolvimento Econômico) e em países convidados, com intuito de avaliar os conhecimentos e competências em Leitura, Matemática e Ciências de estudantes na faixa dos 15 anos (BRASIL, 2010).

230 DOI: Em andamento.

R. Bras. de Ensino de C\&T 
adquira habilidades e competências necessárias à prática cidadã consciente, ou seja, formar um cidadão politizado e com conhecimento necessário para que possa, pautado nele, fazer suas escolhas.

Enquanto a sociedade é bombardeada pelas inúmeras tecnologias que surgem a cada dia, a escola se mantém estagnada, à margem dessa realidade, mesmo que de forma não intencional. Essa dicotomia - o fazer escolar e as NTICE - se apresenta como desafio a ser pesquisado, principalmente pela necessidade de preparar os jovens para atuarem em uma sociedade digital, que exige o domínio da leitura e da escrita também no mundo virtual.

Como ensinar numa concepção de letramento, em um mundo repleto de informações disseminadas pelas NTICE? Que novos desafios se apresentam aos educadores? Quais são as necessidades impostas à escola pela sociedade digital? Esses questionamentos certamente se apresentam como desafios aos profissionais da educação.

A educação formal deve promover a formação do aluno no contexto das mudanças tecnológicas que envolvem o uso da internet, em especial a interatividade das redes sociais, além de criar espaços próprios no ciberespaço para que alunos e professores possam ampliar e promover debates sobre os conteúdos ministrados em sala, colaborando para o letramento.

Nesse contexto, podemos perceber que o uso das NTICE se justifica, pois se apresentam como ferramentas inovadoras, criativas e pouco exploradas pela escola e pelos professores, sendo capazes de dar uma nova dimensão quanto ao tempo e ao espaço dedicados à aprendizagem. Além disso, ensinar nesse novo contexto de sociedade da informação apresenta-se também como um novo espaço de atuação para o professor (MORAN, 2004), qual seja, o virtual. Envolve, portanto, o desenvolvimento das competências em leitura e escrita no ciberespaço.

De acordo com os PCNs "a contribuição da escola, portanto, é a de desenvolver um projeto de educação comprometida com o desenvolvimento de capacidades que permitam intervir na realidade para transformá-la" (BRASIL, 1997, p.20), promovendo assim uma construção contextualizada dos conteúdos estudados. Nas palavras de Moran (2000, p. 137):

“Educar é colaborar para que professores e alunos - nas escolas e organizações - transformem suas vidas em processos permanentes de aprendizagem... Uma mudança qualitativa no processo de ensino/aprendizagem acontece quando conseguimos integrar dentro de uma visão inovadora todas as tecnologias: as telemáticas, as audiovisuais, as textuais, as orais, musicais, lúdicas e corporais... É importante diversificar as formas de dar aula, de realizar atividades, de avaliar"

Inúmeras estratégias pedagógicas têm sido pesquisadas a fim de motivar os alunos a se envolverem em pesquisas e a participarem efetivamente de discussões que complementem e contextualizem as informações transmitidas em sala de aula. Apesar da maioria dos alunos terem 
acesso à internet e a usarem para inúmeros fins, pesquisas escolares inclusive, isso não se traduz em uma aprendizagem efetiva que colabore para a aquisição de competências de letramento.

Para Biancardi, Gonçalves e Espírito Santo (2000), a pesquisa escolar em tempo de transição deve considerar e aprimorar a forma como os alunos usam a internet como recurso de pesquisa, caso contrário, ela será utilizada simplesmente como forma de copiar os trabalhos solicitados pelos professores.

Diante disso, "formar para as novas tecnologias é formar o julgamento, o senso crítico, o pensamento hipotético e dedutivo, as faculdades de observação e de pesquisa, a imaginação e a capacidade de memorizar e classificar" (PERRENOUD,2000, p.128).

Contudo destacamos que, ao optar por uma proposta pedagógica de uso das NTICE, o professor deve estar disposto a um gerenciamento democrático que possibilite a formação de indivíduos capazes de realizar leitura crítica dos meios, desenvolvendo a capacidade de argumentação crítica, escrita e oral.

Essa interação entre gerações - imigrantes e nativos digitais - em torno das ferramentas tecnológicas pode favorecer e estreitar as relações entre professores e alunos e entre os próprios alunos. Dessa forma, ao fazer valer as NTICE na aprendizagem formal, pretende-se tornar o processo ensino/aprendizagem mais democrático e prazeroso, pois proporciona conflitos de ideias e opiniões que permitem uma reflexão crítica, aperfeiçoada no exercício do diálogo, da autoria e coautoria, bem como a reinterpretação de conceitos e práticas; saberes estes fundamentais para que um indivíduo compreenda diversos gêneros textuais relacionados ao saber científico, ou seja, o desenvolvimento de tais competências favorece o letramento científico.

\section{Considerações finais}

Percebe-se que as competências e habilidades relacionadas ao domínio da escrita e da leitura têm mudado de acordo com as exigências estabelecidas pela própria evolução da sociedade. Tais mudanças acarretam novas demandas à escola no que diz respeito a sua função social: a de preparar o educando para atuar de maneira capacitada e eficaz na sociedade.

Na sociedade da informação, isso engloba preparar o educando para lidar com o mundo letrado digitalmente. As NTICE têm-se incorporado às necessidades do mundo globalizado e dado aos usuários a capacidade de articular e trocar informações das mais diversas naturezas. Porém, saber lidar com o grande volume de informação, delimitando e selecionando as informações pertinentes e confiáveis é um dos desafios a ser enfrentado pelos educadores.

Além disso, é necessário que se ampliem, nos cursos de formação de professores das diversas áreas, a discussão e a proposição da inserção de propostas metodológicas que envolvam 
à formação leitora e escritora dos alunos. Tal capacitação também deve ser proporcionada por meio de políticas públicas de incentivo à capacitação docente.

Outro ponto a ser debatido na formação inicial e continuada é o letramento científico dos alunos, que não deve ser delegado somente aos professores das disciplinas exatas, mas ser percebido e desenvolvido em conjunto com outras áreas em projetos interdisciplinares que envolvam uma formação ampla do aluno, no sentido de compreender, assimilar e usufruir do conhecimento científico e tecnológico em suas práticas cotidianas. Trata-se, portanto, de uma necessária readequação curricular das licenciaturas de forma a atender as especificidades da formação do cidadão para o mundo real e virtual.

No exposto, as NTICE apresentam forte potencial pedagógico a ser explorado pelos educadores. Para isso é necessário que os professores assumam seu papel de mediadores, interferindo, apontando, discutindo com os alunos, ouvindo-os, enfim, adotando uma postura que colabore e faça com que os seus alunos sejam protagonistas no processo de aprendizagem. Para tanto, é necessário delegar-Ihes autonomia e propiciar o diálogo franco e aberto, de modo que possam assumir a responsabilidade de aprender. É preciso arriscar, avaliando as atividades propostas, remodelando-as de acordo com as necessidades apresentadas e com os objetivos propostos.

Adotar essa conduta inovadora exige repensar as próprias ações metodológicas e a atitude como docente, que assume seu papel de mediador, orientador e aprendiz, uma vez que a própria dinâmica estabelecida em projetos que envolvem as NTICE exige dos envolvidos uma postura de interação, colaboração e, consequentemente, de aprendizagem mútua.

\section{Referências}

BIANCARDI, A. M. R.; GONÇALVES, A. C.; ESPÍRITO SANTO, E. L. A pesquisa escolar em tempo de transição: estudo de caso. In: CONGRESSO BRASILEIRO DE BIBLIOTECONOMIA E DOCUMENTAÇÃO, 19., Porto Alegre. Anais ... Porto Alegre: 2000.

BIANCONI, M. L.; CARUSO, F. Educação não-formal. Ciência \& Cultura, São Paulo, v. 57, n. 4, p. 1-

3, 2005. Disponível em: <http://cienciaecultura.bvs.br/scielo.php?pid=s0009-

67252005000400013\&script=sci_arttext>. Acesso em: 05 maio 2013.

BRASIL. Ministério da Educação e do Desporto. Secretaria de Educação Fundamental. Parâmetros

Curriculares Nacionais: Introdução aos Parâmetros Curriculares Nacionais. Brasília: SEF, 1997. . Ministério da Educação e do Desporto. Parâmetros Curriculares Nacionais: Ensino

Médio- PCNEM, Parte II - Linguagens, códigos e suas tecnologias. Brasília, 2000. . Plano Nacional de Educação. PNE no 10.172. Brasília: Senado Federal, 2001. 
. Ministério da Educação e do Desporto. Secretaria de Educação Básica. Ensino

Fundamental de Nove Anos: orientações gerais. 2004. Disponível em: <www.mec.gov.br>. Acesso em: 20 nov. 2012.

Programa Internacional de Avaliação de Alunos - PISA. Results: What Students Know and Can Do: Student Performance in Reading, Mathematics and Science. v. I, OECD Publishing, 2010. Disponível em: <http://www.inep.gov.br/download/internacional/pisa/2010/Pisa2009-

vol1_What_students_know_and_can_do.pdf $>$. Acesso em: 22 jan. 2012.

CASTELLS, M. A rede torna mais difícil a opressão, diz Manuel Castells. [09 de junho, 2013]. Jornal Zero Hora [on line]. Entrevista concedida a Carlos André Moreira. Disponível em: < http://zerohora.clicrbs.com.br/rs/cultura-e-lazer/segundo-caderno/noticia/2013/06/a-redetorna-mais-dificil-a-opressao-diz-manuel-castells-4164803.html>. Acesso em: 01 ago. 2013.

FREIRE, P. Educação como prática da liberdade. Rio de Janeiro: Paz e Terra, 1967. 150 p.

Cartas à Guiné-Bissau: registros de uma experiência em Processo. 2. ed., Rio de Janeiro: Paz e Terra, 1978, 173 p.

A experiência do MOVA. SP/ Brasil. Ministério da Educação e Desporto. Instituto Paulo Freire; Organização de Moacir Gadotti. São Paulo, 1996.

HAZEN, R. Why Should You Be Scientifically Literate? Scearce: Scientific Literacy, USA, p. 30-33, 2002.

HAZEN, R. M.; TREFIL, J. Saber ciência. São Paulo: Cultura, 1995.

LÉVY, P. A inteligência coletiva: por uma antropologia do ciberespaço. Trad. Luiz Paulo Rouanet. 2. ed. São Paulo: Loyola, 1999.

MAMEDE, M. A; ZIMMERMANN, É. Letramento científico e CTS na formação de professores para o ensino de física. XVI Simpósio Nacional de Ensino de Física. 2005.

MARTINS, M. H. O que é leitura? 19 ed. São Paulo: Brasiliense, 1994.

MORAN, J. M. Ensino e aprendizagem inovadores com tecnologias. Revista Informática na Educação: Teoria \& Prática. Programa de Pós-Graduação em Informática na Educação. Porto Alegre, v. 3, n.1, UFRGS, p. 137-144, set. 2000.

. Os novos espaços de atuação do professor com as tecnologias. Revista Diálogo

Educacional. Curitiba: PUC-PR, v.4, n.12, maio-ago, 2004, p. 13-21.

PEREIRA, C. M.; MARQUES, V. P.; TORRES, E. F. Dos tempos da caverna ao computador. In: Revista Universidade e Sociedade, Ano 13, n. 17, p. 28-30, jun. 1998.

PERRENOUD, P. Dez novas competências para ensinar. Porto Alegre: Artes Médicas, 2000. PRENSKY, M. Digital Natives, Digital Immigrants. MCB University Press, v. 9, n. 5, 2001. 
PINHO, A. Educação: estudo reforça a ideia de que a repetência prejudica o aluno. [15 de novembro, 2012]. Revista Época. [on line]. Disponível em:< http://revistaepoca.globo.com/Sociedade/noticia/2012/09/educacao-estudo-reforca-ideia-deque-repetencia-prejudica-o-aluno.html>. Acesso em: 24 mar. 2013.

SANTOS, W. L. P. Educação científica na perspectiva de letramento como prática social: funções, princípios e desafios. Revista Brasileira de Educação. [online], vol.12, n.36, pp. 474-492, 2007. SOARES, M. O que é letramento e alfabetização. In: SOARES, M. Letramento: um tema em três gêneros. Belo Horizonte: Autêntica, 1998.

Alfabetização e Letramento. São Paulo: Contexto, 2003.

Lucy Mirian Campos Tavares Nascimento - Mestre em Ensino de Ciências - UnB - Universidade de Brasília. Professora de Biologia/Educação do IFG - Instituto Federal de Educação, Ciência e Tecnologia de Goiás, campus Formosa. lucycmb@gmail.com

Lenise Aparecida Martins Garcia - Doutora em Microbiologia e Imunologia - USP- Universidade de São Paulo. Professora e orientadora do Mestrado Profissional em Ensino de Ciências da UnBUniversidade de Brasília. Igarcia@unb.br

DOI: Em andamento. 